\title{
Grey Relational Degree-based Old People Physical Exercises Influences on Physical Health
}

\author{
Fali Zhang*
}

Department of Military Physical Education, Jilin Agricultural University, Changchun 130118, Jilin, China

\begin{abstract}
With rapidly development of Chinese economy, aged population is also constantly increasing. By far, China has already been regarded as "aging" country. How to enhance old people physique, guarantee the old physical health , prolonging life-span has become an important topic of current society, so physical exercises that are closely related to health also attracts more and more old people attentions. The paper makes specific analysis of old people physical exercises consciousness, motivation, sports places' conditions, relationship between whether participating in sports activities and prevalence rate, the old participate in physical exercises influence factors, old people physical exercises efficiency and other situations, it gets old people physical activities existing problems in development process, and puts forward reform measures. Apply grey relational degree method; establish grey relational degree-based old people physical exercise to physical health influence model, by calculating old people physical exercises duration、intensity frequency and health index correlation degree values, and then get that old people physical exercise frequency has the largest impacts on physical health, old people should increase physical exercise frequency to keep fit.
\end{abstract}

Keywords: Aged sports, grey relational degree, health index, physical exercise, physical health.

\section{INTRODUCTION}

When going into aged stage, each organ of body is also constantly aging with the increase of age, physiological function is also constantly declining, which causes old people occurring to physical quality gradually declination, activities being hindered, and barely walk [1]. With constantly development of physical exercise in society, old people are aware of physical exercise influences on physical health, accordingly also constantly join in the group of physical exercise [2].

In 2012, Zhang Hou-Chen in the article "Dalian City old people sports activities status and counter measures study in the background of aging of population, took Dalian downtown old people sports activities as research objects, adopted multiple methods to make comprehensive analysis of their current situations, found out present Dalian downtown old people sports activities existing problems, and put forward corresponding measures for the problems [3]. In 2012, Li Yang-Yang in the article "Jinan City old people physical exercise status investigation and research", by researching on old people physical exercise importance, old people sports lifestyle, old people physical exercise and physical and psychological health relationships, got conclusion that old people physical exercise not only could build their bodies but also could promote psychological health, reduce disease [4].

Therefore, we should encourage old people to participate in sports activities and often take exercises. In 2008, Zhang Hui in the article "Chinese old people physical exercises relevant issues research summary", researched on old people physical exercise duration, motivation, physical exercise items, physical exercise obstructive factors, physical exercise fields and else, found that present Chinese old people physical exercise had lots of deficiency, and put forward suggestions on this basis, which made contributions for future research orientations [5].

The paper makes comprehensive analysis of old people physical exercise conditions, and puts forward corresponding suggestions on existing problems [6]. On this basis, utilize grey relational degree method, establish grey relational degree-based old people physical exercise to physical health influence model, by calculating old people physical exercise duration, intensity, frequency and health index correlation values, and further gets that old people physical exercise frequency has the largest impacts on physical health.

\section{OLD PEOPLE PHYSICAL EXERCISE STATUS}

With the improvement of people's living quality, people more and more focus on physical health, especially for the old, while physical exercise not only can promote physical health and psychological health, but also can enhance the old physique, improve capacity for action, reduce diseases, and prevent senile dementia. Therefore, physical exercise has become an indispensable part of old people's life.

\subsection{Old People Physical Exercise Consciousness}

The key factor that whether old people can proactive participate in sports activities and strengthen physical exercise is their awareness of importance of physical exercise.

By above data Table 1, we can see that most of old people think physical exercise is very important to physical 
Table 1. Old people understanding of physical exercise importance.

\begin{tabular}{|c|c|c|c|}
\hline $\mathbf{N}$ & Very important & Not so important & Not important \\
\hline \hline 483 & 305 & 151 & 27 \\
\hline$\%$ & 63.1 & 31.3 & 5.6 \\
\hline
\end{tabular}

Table 2. Motivation of different age groups old people participating in physical exercise.

\begin{tabular}{|c|c|c|c|c|c|c|}
\hline & Body building & $\begin{array}{c}\text { Pastime and } \\
\text { entertainment }\end{array}$ & Treat the disease & Social contact & $\begin{array}{c}\text { Lose weight and } \\
\text { beauty building }\end{array}$ & $\begin{array}{c}\text { Improve sports } \\
\text { activities }\end{array}$ \\
\hline \hline $60-64$ & $12.5 \%$ & $37.9 \%$ & $9.3 \%$ & $62.7 \%$ & $50 \%$ & $40 \%$ \\
\hline $65-69$ & $36.3 \%$ & $30.1 \%$ & $10.3 \%$ & $25.5 \%$ & $34.2 \%$ & 0 \\
\hline $70-74$ & $32.2 \%$ & $26.2 \%$ & $34.6 \%$ & $5.9 \%$ & $10.5 \%$ & 0 \\
\hline $75-79$ & $10.1 \%$ & 0 & $38.3 \%$ & $5.9 \%$ & $2.6 \%$ & $60 \%$ \\
\hline Above 80 & $8.9 \%$ & $5.8 \%$ & $7.5 \%$ & 0 & $2.6 \%$ & 0 \\
\hline
\end{tabular}

Table 3. Old people sports places distribution status.

\begin{tabular}{|c|c|c|c|c|c|c|c|}
\hline Place & $\begin{array}{c}\text { Park free of } \\
\text { charge }\end{array}$ & Leisure square & Residential space & $\begin{array}{c}\text { Residential court- } \\
\text { yard }\end{array}$ & $\begin{array}{c}\text { Profit-making } \\
\text { stadiums }\end{array}$ & $\begin{array}{c}\text { School sports } \\
\text { venues }\end{array}$ & Else \\
\hline \hline Number of people & 304 & 116 & 195 & 54 & 26 & 13 \\
\hline Percentage (\%) & 40.2 & 15.3 & 25.8 & 7.1 & 3.5 & 6.4 \\
\hline Ranking & 1 & 3 & 2 & 4 & 6 & 5 \\
\hline
\end{tabular}

health that occupy $63 . \%$, old people that think physical exercise is not so important occupy $31.3 \%$, only $5.6 \%$ old people think physical exercise is not important. In order to guarantee old people physical health, we should strengthen publicity of physical exercise impacts on physical health; enhance old people consciousness of physical exercise.

\subsection{Old People Motivation in Participating in Physical Exercise}

When people go into retired stage, and meanwhile step into the old, such kind of people have more leisure time, and activities performing is gradually declining, they realize physical exercise has benefits both in physical health and psychological health, accordingly would participate in physical exercise according to their age, body, psychological each aspect demands. Below Table $\mathbf{2}$ is motivation of different age groups old people participating in physical exercise.

From data indication of motivation of different age groups old people participating in physical exercise, it can analyze that old people in the age group of 60 to 64 years old prefer to social contact and lose weight as well as beauty building, and old people in the age group of 65 to 69 years old tend to body building, lose weight and beauty building , pastime and entertainment. Old people in the age group of 70 to 74 focus on treating disease, body building. Old people in the age group of 75 to 79 lay more emphasis on improving sports activities. While people above 80 years old because of older age, little participate in physical exercise that is mainly body building , treating the disease. Different age groups old people have different motivations in participating in physical exercise due to physical quality difference.

\subsection{Old People Sports Places Status}

From above Table $\mathbf{3}$, it is clear that old people mainly take exercise in park free of charge that occupy $40.2 \%$, secondly is residential space that occupies $25.8 \%$, the third is leisure square that occupies $15.3 \%$, other places are in order residential courtyard, school sports venues, profit-making stadiums and else. Therefore, it is clear that old people more take part in sports activities in places free of charge. In order to strengthen old people physical exercise, government should establish more indoors places to fit for old people physical exercise, and offer to old people physical exercise for free.

\subsection{Relationship between Whether Participating in Physical Fitness Activities and Prevalence Rate}

With constantly increment of ages, old people physical quality declines, accordingly prevalence rate also grows, participate in physical fitness not only can build body, keep a good mood, but also can reduce incidence of diseases. 
Table 4. Relationship between whether participating in physical fitness and prevalence rate.

\begin{tabular}{|c|c|c|c|c|}
\hline & \multicolumn{2}{|c|}{ Not fall ill } & \multicolumn{2}{|c|}{ Fall ill } \\
\hline Haven't participated in physical fitness & 4 & 21 & 15 & 79 \\
\hline
\end{tabular}

Table 5. Old people participate in physical exercise influence factors (600 people in total).

\begin{tabular}{|c|c|c|c|c|c|c|c|c|c|}
\hline $\begin{array}{l}\text { Lack of fields } \\
\text { and facilities }\end{array}$ & $\begin{array}{l}\text { Short of } \\
\text { time }\end{array}$ & $\begin{array}{c}\text { Lack of } \\
\text { organization }\end{array}$ & $\begin{array}{c}\text { Lack of sports } \\
\text { partners }\end{array}$ & $\begin{array}{l}\text { Have no } \\
\text { interests }\end{array}$ & $\begin{array}{l}\text { Slug- } \\
\text { gishness }\end{array}$ & $\begin{array}{l}\text { Economic condi- } \\
\text { tions constraint }\end{array}$ & $\begin{array}{c}\text { Feel } \\
\text { unwell }\end{array}$ & $\begin{array}{l}\text { No influence } \\
\text { factors }\end{array}$ & Else \\
\hline 236 & 158 & 148 & 8 & 58 & 46 & 8 & 172 & 16 & 68 \\
\hline $39.3 \%$ & $26.3 \%$ & $24.7 \%$ & $1.3 \%$ & $9.7 \%$ & $7.7 \%$ & $1.3 \%$ & $28.7 \%$ & $2.7 \%$ & $11.3 \%$ \\
\hline
\end{tabular}

Table 6. Old people physical exercise impacts on physical health.

\begin{tabular}{|c|c|c|c|c|}
\hline Physical exercise way & Old people health index & $\begin{array}{c}\text { Physical exercise intensity } \\
\text { (moderate perspiration)\% }\end{array}$ & $\begin{array}{c}\text { Physical exercise (week) } \\
\text { frequency (3-4 times)\% }\end{array}$ & $\begin{array}{c}\text { Physical exercise duration } \\
\text { (Above 60 minutes)\% }\end{array}$ \\
\hline \hline Square dance & 34.2 & 36.1 & 32.4 & 46.3 \\
\hline Social dance & 10.2 & 23.4 & 25.1 & 13.8 \\
\hline Long distance walking & 29.5 & 13 & 20.6 & 30.3 \\
\hline Qigong Tai Chi & 26.1 & 27.5 & 21.9 & 9.6 \\
\hline
\end{tabular}

By "Whether old people participate in physical exercise and prevalence relationship" data Table 4, it is clear that prevalence rates of old people participate in physical fitness and those haven't participated in physical fitness are different, prevalence rate of old people participate in physical fitness is $66.8 \%$, while $79 \%$ prevalence rate is from old people that haven't participated in physical fitness. Therefore, participate in physical exercise can reduce occurrence of old people diseases; we should encourage more old people to join in the group of physical exercise.

\subsection{Old People Participate in Physical Exercise Influence Factors}

Old people participate in physical exercise suffers multiple factors influence, as following Table $\mathbf{5}$ shows:

By Table 5, it is clear that main factor affects old people participate in physical exercise is lack of fields and facilities that occupies $39.3 \%$ of total factors, the second influence factor is old people feeling unwell that occupies $28.7 \%$, the third influence factor is old people short of time that occupies $24.7 \%$. The fourth influence factor is lack of organization that occupies $24.7 \%$. By above analysis, it is clear that main causes are imperfect physical exercise fields and facilities for old people, old people physical quality declination and old people lack of exercise time, government should improve old people exercise fields' facilities to provide a good exercise fields and exercise environment for the old, so as to promote more old people to participate in physical exercises, and meanwhile as children, we should more focus on the old physical health, offer more time to the old, not let them to be busy with domestic chores and babies but let them to more participate in physical exercise activities, which not only can enhance physical quality but also cultivate their taste.

\subsection{Old People Physical Exercise Efficiency Analysis}

Physical exercise is good for physical and psychological health, especially for the old, best method that proves old people physical exercise efficiency is old people subjective feeling after physical exercise. By above data indication, it is clear that old people feel quite related when taking physical exercise within 30minutes occupy $42.3 \%$; the ones feel relaxed in 30 to 60 minutes occupy $29.8 \%$, while the ones feel relaxed above 60 minutes occupy $33.8 \%$, thereupon, when old people take physical exercise of big sports intensity, exercise duration is shorter, when old people take physical exercise of relative smaller sports intensity, exercise duration is relative longer. Old people that think physical exercise is very important will feel more relaxed after physical exercise than the ones think physical exercise is not so important and not important. Old people think physical exercise is not important lack of consciousness of physical exercise. By physical exercise motivation and after exercising subjective feeling analysis, it is clear that most of old people that take physical exercise aims at body building will feel tired, and old people take physical exercise for the purposes of pastime and entertainment, treating the disease social contact will feel quite relaxed, it shows these sports intensity is smaller. 


\subsection{Grey Relational Degree Method-based Old People Physical Exercise Impacts on Physical Health}

On the basis of researching on Chinese old people physical exercise status, it is clear that now more and more old people constantly join in the group of physical exercise. In order to make quantitative analysis of Chinese old people physical exercise impacts on physical health, it utilizes mathematics grey relational degree method to research on Chinese old people physical exercise duration, frequency and intensity, and then gets correlation conclusions.

Below Table 6 is data table about old people physical exercise impacts on physical health, it mainly takes old people favorite square dance, social dance, long distance walking, Qigong Tai Chi sport events as research objects, old people health index in the table refers to healthy old people's proportion to whole old people after all kinds of physical exercises, data is from China statistical yearbook:

Grey relational analysis is further analyzing factors impacts o research objects by calculating factors and research objects correlations, it bases on systematic overall development and changes, if systematic changes and factors changes trends are consistent, then the two correlations are larger; if systematic changes are inconsistent to factor changes trends, or have certain differences, then the two correlations are smaller.

Record Chinese old people physical health influence factor feature behaviors sequence as following:

$x_{i}^{\prime}=\left(x_{i}^{\prime}(1), x_{i}^{\prime}(2), x_{i}^{\prime}(3)\right)^{T}, i=1,2,3$

from which correlation factor line sequence is:

$x_{1}^{\prime}=(36.1,23.4,13,27.5)$;

$x_{2}{ }^{\prime}=(32 \cdot 4,25 \cdot 1,20 \cdot 6,21 \cdot 9)$;

$x_{3}^{\prime}=(46.3,13.8,30.3,9.6)$

Thereupon, it can get:

$x_{i}^{\prime}=\left(\begin{array}{cccc}36.1 & 23.4 & 13 & 27.5 \\ 32.4 & 25.1 & 20.6 & 21.9 \\ 46.3 & 13.8 & 30.3 & 9.6\end{array}\right)$

Define reference sequence:

Take Chinese old people health index sequence $x_{0}^{\prime}$ as reference sequence, that is: $x_{0}^{\prime}=(34.2,10.2,29.5,26.1)$

Initialization method data processing:

Utilize formula

$x_{i}(k)=\frac{x_{i}^{\prime}(k)}{x_{i}^{\prime}(1)}$,

to handle with relative factors line sequence, result is as following :

$$
x_{1}(k)=\frac{x_{1}^{\prime}(k)}{x_{1}^{\prime}(1)}=(1,0.65,0.36,0.76)
$$

$$
\begin{aligned}
& x_{2}(k)=\frac{x_{2}^{\prime}(k)}{x_{2}^{\prime}(1)}=(1,0.77,0.64,0.68) ; \\
& x_{3}(k)=\frac{x_{3}^{\prime}(k)}{x_{3}^{\prime}(1)}=(1,0.30,0.65,0.21)
\end{aligned}
$$

Calculate $\min _{1 \leq i \leq 3} \min _{1 \leq k \leq 4}\left|x_{0}^{\prime}-x_{i}(k)\right|, \max _{1 \leq i \leq 3} \max _{1 \leq k \leq 4}\left|x_{0}^{\prime}-x_{i}(k)\right|$

Input

$$
\begin{aligned}
& x_{1}(k)=(1,0.65,0.36,0.76) ; \\
& x_{2}(k)=(1,0.77,0.64,0.68) ; \\
& x_{3}(k)=(1,0.30,0.65,0.21) ; \\
& x_{0}{ }^{\prime}=(34.2,10.2,29.5,26.1)
\end{aligned}
$$

into above formula and can get:

$\min _{1 \leq i \leq 3} \min _{1 \leq k \leq 4}\left|x_{0}{ }^{\prime}-x_{i}(k)\right|=51.68 \max _{1 \leq i \leq 3} \max _{1 \leq k \leq 4}\left|x_{0}{ }^{\prime}-x_{i}(k)\right|=51.99$

Calculate correlation coefficient:

Below is correlation coefficient computational formula:

$\zeta_{i}(k)=\frac{\operatorname{minmin}_{1 \leq i \leq n}\left|x_{1 \leq k \leq m}^{\prime}(k)-x_{i}(k)\right|+\rho \times \max _{1 \leq i \leq n} \max _{1 \leq k \leq m}\left|x_{0}^{\prime}(k)-x_{i}(k)\right|}{\left|x_{0}^{\prime}(k)-x_{i}(k)\right|+\rho \times \max _{1 \leq i \leq n} \max _{1 \leq k \leq m}\left|x_{0}^{\prime}(k)-x_{i}(k)\right|}$

Among them, $\rho$ is resolution ratio, and $\rho \in(0,1)$, $\rho=0.5, \rho$ gets bigger and then relation is bigger.

$$
\text { Input }\left|x_{0}^{\prime}(k)-x_{i}(k)\right| \text { each value, and can solve: }
$$

$$
\begin{aligned}
& \zeta_{1}=(1.312,2.186,1.402,1.513) ; \\
& \zeta_{2}=(1.312,2.193,1.416,1.511) ; \\
& \zeta_{3}=(1.312,2.164,1.416,1.497)
\end{aligned}
$$

Calculate correlation degree:

Use correlation degree computational formula

$$
r_{i}=\frac{1}{m} \sum_{k=1}^{m} \zeta_{i}(k)
$$

Input:

$$
\begin{aligned}
& \zeta_{1}=(1.312,2.186,1.402,1.513) ; \\
& \zeta_{2}=(1.312,2.193,1.416,1.511) ; \\
& \zeta_{3}=(1.312,2.164,1.416,1.497)
\end{aligned}
$$

And get: $r_{1}=1.603, r_{2}=1.608, r_{3}=1.597$

Evaluation results:

It can get conclusions that for Chinese old people physical exercise, it is weekly physical exercise frequency that has largest impacts on physical health, its correlation value is 1.608 , secondly is physical exercise intensity, correlation value is 1.603 , finally is physical exercise 
duration, correlation value is 1.597. Grey correlation calculation can define the three factors regarding Chinese old people physical exercise impacts on physical health. Though three factors and Chinese old people physical exercise correlations with physical health are different, each correlation has no big differences, therefore, when researching on old people physical exercise impacts on physical health in future, it should take comprehensive consideration of the three factors.

\section{CONCLUSION}

Firstly, the paper analyzes old people physical exercise status, and puts forward suggestions on current problems. By making specific analysis of old people physical exercise consciousness, motivation, places, influence factors, efficiency after exercises, and then further get conclusion $\mathrm{s}$ that in order to better promote old people physical exercise development, it not only needs old people to enhance physical exercise consciousness, but also needs government to increase construction for old people physical exercise.

According to old people physical exercise duration, intensity, frequency impacts on health index, the paper establishes correlation model that old people physical exercise impacts on physical health, by calculating old people physical exercise duration, intensity, frequency and health index correlations, and then it gets that old people physical exercise frequency has the largest impacts on physical health, old people should increase physical exercise frequency for physical and psychological health.

\section{CONFLICT OF INTEREST}

The authors confirm that this article content has no conflict of interest.

\section{ACKNOWLEDGEMENTS}

Declared none.

\section{REFERENCES}

[1] J. Liu, "Comparative research on difference between body shape and function and physical fitness of college students for different body-mass index level", Journal of Pla Institute of Physical Education, vol. 30, no. 1, pp. 125-128, 2011.

[2] Y. Li, and C. Huang, "Influence of sports self-concept and selfefficacy on sports practice of university students," Journal of Sports Adult Education, vol. 27, no. 6, pp. 32-35, 2011.

[3] H. Lu, L. Li, L. Liu, X. Lv, and L. Yuan, "The analysis and research of the comprehensive intervention measures on over-weight or obesity middle-aged groups in hebei province," Journal of Hebei Institute of Physical Education, vol. 22, no. 6, 2008.

[4] J. Ning, "Study of transformation of college students' exercise methods," Bulletin of Sport Science \& Technology, vol. 21, no. 4, pp. 85-87, 90, 2013.

[5] D. Shi, and G. Yang, "Study on physical characteristics and influencing factors of fat students with difference physical exercise," Journal of Hubei Sports Science, vol. 32, no. 3, pp. 215-217, 2013.

[6] Q. Yu, and H. Xu, "Research on the differences of spare time exercise behavior between two different body weight students," Zhejiang Sport Science, vol. 35, no. 5, pp. 78-80, 2013.

\footnotetext{
Received: May 26, 2015

Revised: July 14, 2015

Accepted: August 10, 2015

(C) Fali Zhang; Licensee Bentham Open.

This is an open access article licensed under the terms of the (https://creativecommons.org/licenses/by/4.0/legalcode), which permits unrestricted, noncommercial use, distribution and reproduction in any medium, provided the work is properly cited.
} 